\title{
Supramaximal Stimuli Do Not Evoke a Maximal Contraction in Urinary Bladder Smooth Muscle Fibers
}

\author{
Joanne Minekus Anna J. Visser Ron van Mastrigt \\ Department of Urology-Urodynamics, Erasmus University of Rotterdam, The Netherlands
}

\section{Key Words}

Detrusor $\cdot$ Smooth muscle $\cdot$ Stimulation $\cdot$ Carbachol ·

Electrical field $\cdot$ Potassium $\cdot$ Contraction

\begin{abstract}
Background: Smooth muscle fibers can be stimulated with an electrical field, high potassium or carbachol. We studied the effect of combined, supramaximal stimulation on the isometric force and the maximum shortening velocity of the pig urinary bladder. Materials and Methods: After determining the dose response curve of each stimulation type, we stimulated 8 fibers with cumulative addition of supramaximal stimuli. Results: The isometric force elicited with either potassium, carbachol or electrical field stimulation alone was the same for each stimulus. After addition of a second or third different supramaximal stimulus, the force further increased to a value that was on average $40 \%$ higher. Conclusions: Carbachol, high potassium or electrical field stimulation work through different stimulation pathways. Maximum stimulation with one of the stimuli does not result in a maximum isometric force development and maximum short-
\end{abstract} ening velocity.

Copyright $@ 2001$ S. Karger AG, Basel

\section{Introduction}

In smooth muscle fibers of the urinary bladder, both the isometric force and the maximum shortening velocity depend on the intracellular calcium concentration [1]. This concentration can be increased by opening calcium channels in the cell membrane to enable influx of extracellular calcium or by releasing intracellularly stored calcium. Three different stimulation methods are frequently used: high potassium, electrical field and muscarinic receptor stimulation. High potassium and electrical field stimulation mainly depolarize the cell membrane and thereby open voltage-dependent calcium channels. They may also stimulate the nerves to release acetylcholine. Stimulation of the muscarinic receptors with carbachol or acetylcholine causes release of calcium from intracellular stores and the opening of receptor-bound calcium channels in the cell membrane. Carbachol and acetylcholine may also change the sensitivity of the contractile apparatus for calcium $[2,3]$.

When vascular smooth muscle fibers are stimulated with a combination of supramaximal concentrations of potassium and epinephrine, the calcium concentration in the cell is higher compared to application of one stimulus

\footnotetext{
R. van Mastrigt

Department of Urology-Urodynamics, Room Ee1630

Erasmus University of Rotterdam, PO Box 1738

NL-3000 DR Rotterdam (The Netherlands)

Tel.+31 10 4088058, Fax +31 10 4089451,E-Mail vanmastrigt@udn.fgg.eur.nl
} 
alone [4-6]. This may indicate that in this muscle type high potassium does not fully activate the muscle fiber. In the course of a previous study [7], we found that a combined stimulation with supramaximal concentrations of two different stimuli resulted in a higher force generation compared to application of one of these stimuli alone. In this study, we tested whether stimuli in supramaximal concentrations resulted in a maximum force development and a maximum shortening velocity of smooth muscle fibers of the pig urinary bladder.

\section{Methods}

\section{Tissue Preparation and Incubation}

Urinary bladders of freshly killed pigs were obtained from the local slaughterhouse. Strips of $2 \times 2 \mathrm{~cm}$ were cut from the anterolateral bladder wall and were transported and kept in oxygenated Krebs' solution $\left(\mathrm{NaCl} 118 \mathrm{~m} M ; \mathrm{KCl} 4.7 \mathrm{~m} M ; \mathrm{NaHCO}_{3} 25 \mathrm{~m} M\right.$; $\mathrm{KH}_{2} \mathrm{PO}_{4} 1.2 \mathrm{~m} M ; \mathrm{CaCl}_{2} 1.8 \mathrm{~m} M ; \mathrm{MgSO}_{4} 1.2 \mathrm{~m} M$; glucose $11 \mathrm{~m} M$; $\mathrm{pH}$ 7.4). The strips were stored at $4{ }^{\circ} \mathrm{C}$ and used for 2 consecutive days. Longitudinal muscle fibers of about $5 \times 0.2 \mathrm{~mm}$ were cut from the bladder wall under a binocular microscope. The fibers were transferred to an organ bath containing $0.3 \mathrm{ml}$ Krebs' solution, which was refreshed at a rate of $0.8 \mathrm{ml} / \mathrm{h}$. The fibers were clamped between two pairs of tweezers, one linked to a KG3 force transducer connected to a BAM3 amplifier (Scientific Instruments ${ }^{\circledR}$, Heidelberg, Germany). The other pair of tweezers was attached to a length controller $[7,8]$ which could shorten the muscle fibers at a constant velocity to a preset stop length and later re-stretch them to the pre-shortening length. The measurements were controlled using a computer equipped with a PCL818 A/D converter card driven by locally developed multichannel data acquisition and measurement control software (MKR). Temperature was kept at $37.5 \pm 0.5^{\circ} \mathrm{C}$ using a $200-\mu \mathrm{m}$ diameter thermocouple $\left(\mathrm{Omega}^{\circledR}\right)$ controlling a halogen lamp (Philips ${ }^{\circledR}, 12 \mathrm{~V}$, $20 \mathrm{~W}, 6^{\circ}$, type 6483 ).

Twenty minutes after mounting the fibers, the slack length $\left(1_{s}\right)$, the minimum length at which a passive force changes $( \pm 100 \mu \mathrm{N})$ in response to a slight change in length $( \pm 10 \mu \mathrm{m})$ was visible, was determined. Next the fiber was stretched to its measurement length, which was 1.5-2 times the slack length. After an equilibrium period of $10 \mathrm{~min}$, the first measurement was made. Between two measurements, a resting period of at least $10 \mathrm{~min}$ was allowed. The measurements were stored in the computer and later analyzed with the help of the computer programs MKR and Matlab ${ }^{\circledR}$.

\section{Stimulation Types}

The fibers were stimulated with an electrical field (EFS), carbachol $(\mathrm{CCh})$ or high potassium $\left(\mathrm{K}^{+}\right)$. For each stimulation type, doseresponse curves were made to find the supramaximal dose. For each dose-response curve, five fibers were used. Before each measurement series and after every two measurements a fixed stimulus was applied to serve as a reference. The force responses to experimental stimulus applications were divided by the average force response to the two nearest reference stimulus applications, to normalize the responses and to correct them for time-induced changes in contractility.

Supramaximal Stimuli in Smooth Muscle

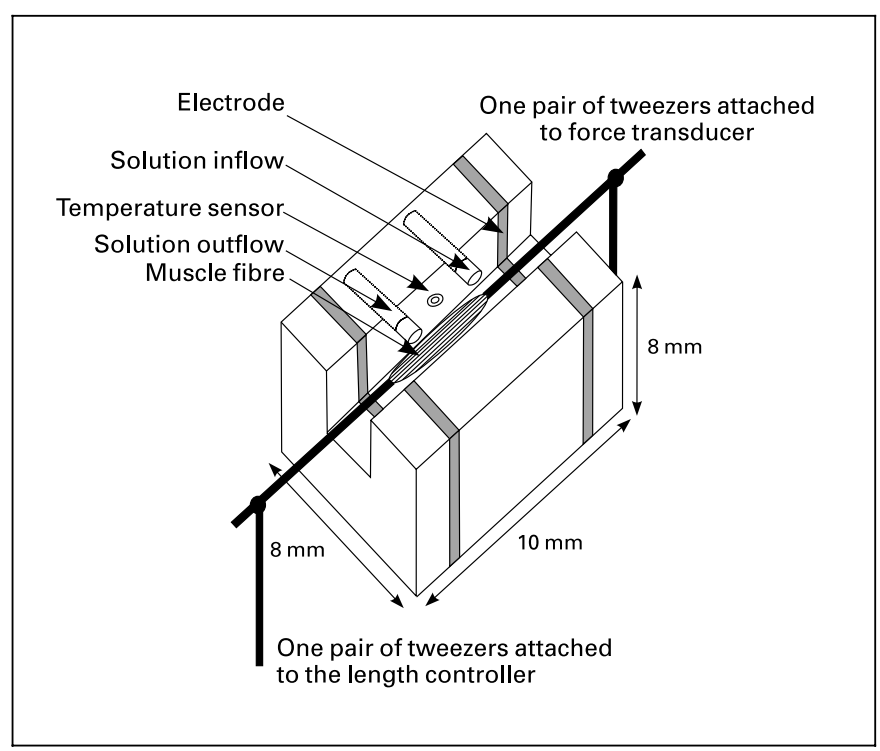

Fig. 1. A schematic drawing of the organ bath. The fiber was clamped between two pairs of tweezers, one connected to a force transducer and the other to a length controller. The groove containing the fiber was filled with Krebs' solution that was continuously refreshed. The temperature was kept constant at $37^{\circ} \mathrm{C}$ using a temperature sensor and an infrared light. The fiber was electrically stimulated via two platinum electrodes. The $\mathrm{CCh}$ and $\mathrm{K}^{+}$solutions were brought into the organ bath by means of an injection needle.

The muscle fibers were electrically stimulated with a field generated by applying alternating biphasic pulses to two platinum electrodes at both ends of the preparation (fig. 1). The dependence of the force on both the repetition rate and the amplitude was tested. The repetition rate $(f)$ was varied between 50 and $2,000 \mathrm{~Hz}$ while the amplitude was fixed at $6 \mathrm{~V}$; the duration of the stimulus pulses was set at 1 divided by 2 times the repetition rate $(1 / 2 f)$. The reference response was measured at a repetition rate of $100 \mathrm{~Hz}$ and a duration of $5 \mathrm{~ms}$. The effect of the amplitude was tested for amplitudes between 2 and $12 \mathrm{~V}$ with a repetition rate of $500 \mathrm{~Hz}$. For this series, stimulation with $6 \mathrm{~V}$ and $500 \mathrm{~Hz}$ was used as a reference.

For muscarinic stimulation the Krebs' solution was instantaneously replaced by a Krebs' solution containing $\mathrm{CCh}$ in a concentration varying between $0.6 \cdot 10^{-3}$ and $1.4 \mathrm{mM}$. A reference concentration of $0.14 \mathrm{~m} M \mathrm{CCh}$ was used. A high $\mathrm{K}^{+}$solution was made by replacing all the sodium in the Krebs' by $\mathrm{K}^{+}\left(119 \mathrm{~m} M \mathrm{~K}^{+}\right)$. This was used as the reference concentration for the dose-response curve of $\mathrm{K}^{+}$. For lower doses of $\mathrm{K}^{+}$only a part of the sodium in the normal Krebs' solution was replaced (concentration ranged between 12.8 and $119 \mathrm{~m} M \mathrm{~K}^{+}$). For stimulation, the Krebs' in the organ bath was replaced by the test solution with high $\mathrm{K}^{+}$within a second. The stimuli were washed out of the organ bath after each measurement.

After determining the concentration of each stimulus needed to get a maximal force response, which was called the supramaximal concentration, 8 fibers were stimulated with all three supramaximal stimuli, which were $8 \mathrm{~V}$ and $500 \mathrm{~Hz}$ for EFS, $119 \mathrm{mM}$ for $\mathrm{K}^{+}$and 


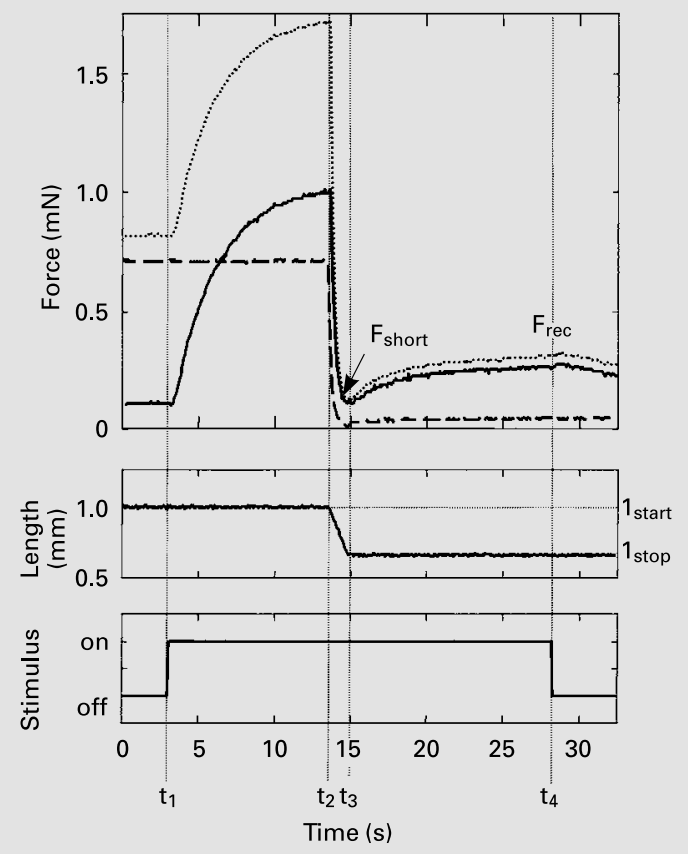

Fig. 2. An example of a force velocity measurement using the stop test technique. At $t_{1}$ the stimulation started, the total force ( $\left.\cdots \cdots \cdot\right)$ rose to a maximum value, while the passive force (---) remained constant. The active force (-) is defined as the total force minus the passive force. The shortening started at $t_{2}$ and both total and passive force dropped. At $t_{3}$ the shortening stopped; the active force at $t_{3}$ is the force during shortening at the stop length $\left(\mathrm{F}_{\text {short }}\right)$. Subsequently the total force rose to a new maximum value $\left(\mathrm{F}_{\text {rec }}\right)$ at $t_{4}$.

$1.4 \mathrm{~m} M$ for $\mathrm{CCh}$. The fibers were first stimulated with one of the three stimuli alone until a maximum force was reached, then a second stimulus was applied. When a new maximum force was reached, the third stimulus was added. Each fiber was stimulated in all six orders of application. The time needed to reach a maximum force varied between 10 and $25 \mathrm{~s}$ and depended on the muscle fiber, the stretched fiber length and the contraction history. The passive force measured just before application of a stimulus was subtracted from the total maximum force attained to calculate the active force response. These values were called the isometric forces. As a reference value, the force in response to EFS with $8 \mathrm{~V}$ and $500 \mathrm{~Hz}$ was used.

\section{Force Velocity Relation}

The maximum shortening velocity was measured using a stop test method [7]. Five fibers were shortened from a variable start length to a fixed stop length at a pre-set velocity maintained for $2 \mathrm{~s}$ (fig. 2). Each measurement was done twice, first without and the second time with stimulation. By subtracting the measurement without stimulation from the measurement with stimulation, the active force response was calculated. The active force during shortening at the stop length was divided by the maximum active force attained after the shortening was stopped and was called the relative force. It depended on the shortening velocity according to a Hill curve [9]. Using this curve, the maximum shortening velocity was calculated. This value was normalized by dividing it by the slack length. For each fiber four maximum shortening velocity values were determined, evoked with either $\mathrm{CCh}$ and $\mathrm{K}^{+}$stimulation alone or with CCh-EFS and $\mathrm{K}^{+}$-EFS. The four velocities were compared with each other and with the maximum shortening velocity measured with EFS in an earlier study [7].

\section{Statistical Analysis}

Values are expressed as mean \pm the standard error of the mean. Using a $t$ test measurements in different fibers were compared. The dependence of force on stimulus intensity was tested using an ANOVA test. When a difference was found, the paired $t$ test was used to compare all measurements in the same muscle fiber. A $p$ value of $<0.05$ was considered to be significant.

\section{Results}

\section{Dose Response Curves}

The isometric force did not depend on the repetition rate of the EFS (fig. 3a; ANOVA, p = 0.193). It increased with increasing amplitude of the EFS (fig. 3b; ANOVA, $\mathrm{p}<0.001$ ) until a plateau was reached at a voltage of $8 \mathrm{~V}$. The response to any tested voltage higher than the threshold value of $8 \mathrm{~V}$ did not significantly differ from the response to $8-\mathrm{V}$ stimulation nor were there differences between responses to voltages above $8 \mathrm{~V}$ (paired $\mathrm{t}$ test, $\mathrm{p}<$ $0.05)$. Furthermore, the responses to stimulation with voltages lower than $8 \mathrm{~V}$ were significantly lower than the response to $8 \mathrm{~V}$ (paired t test, $\mathrm{p}<0.05$ ). By increasing the concentration of $\mathrm{CCh}$ or $\mathrm{K}^{+}$, the isometric force also increased until a force plateau was reached (fig. $3 \mathrm{c}, \mathrm{d}$; ANOVA, $p<0.001$ ) for both stimuli at threshold concentrations of $0.14 \mathrm{~m} M \mathrm{CCh}$ and $95.4 \mathrm{~m} M \mathrm{~K}^{+}$, respectively (paired $t$ tests were done as for the voltage). For further measurements an EFS of $8 \mathrm{~V}$ and $500 \mathrm{~Hz}$, a CCh concentration of $1.4 \mathrm{~m} M$ and a high $\mathrm{K}^{+}$solution of $119 \mathrm{~m} M$ were used.

\section{Cumulative Stimuli}

We did not find any difference between the fibers measured on the 1st or 2 nd day ( $t$ test, data not shown). The muscle fibers $(n=8)$ were stimulated with one of the three stimuli, $\mathrm{CCh}$, high $\mathrm{K}^{+}$or EFS, until a maximum force was reached. The force responses to all three stimuli were normalized by dividing them by the response to an EFS of $8 \mathrm{~V}$ and $500 \mathrm{~Hz}$ and caused an equal force increase (fig. 4; ANOVA, $p=0.492)$. When a maximum force was 

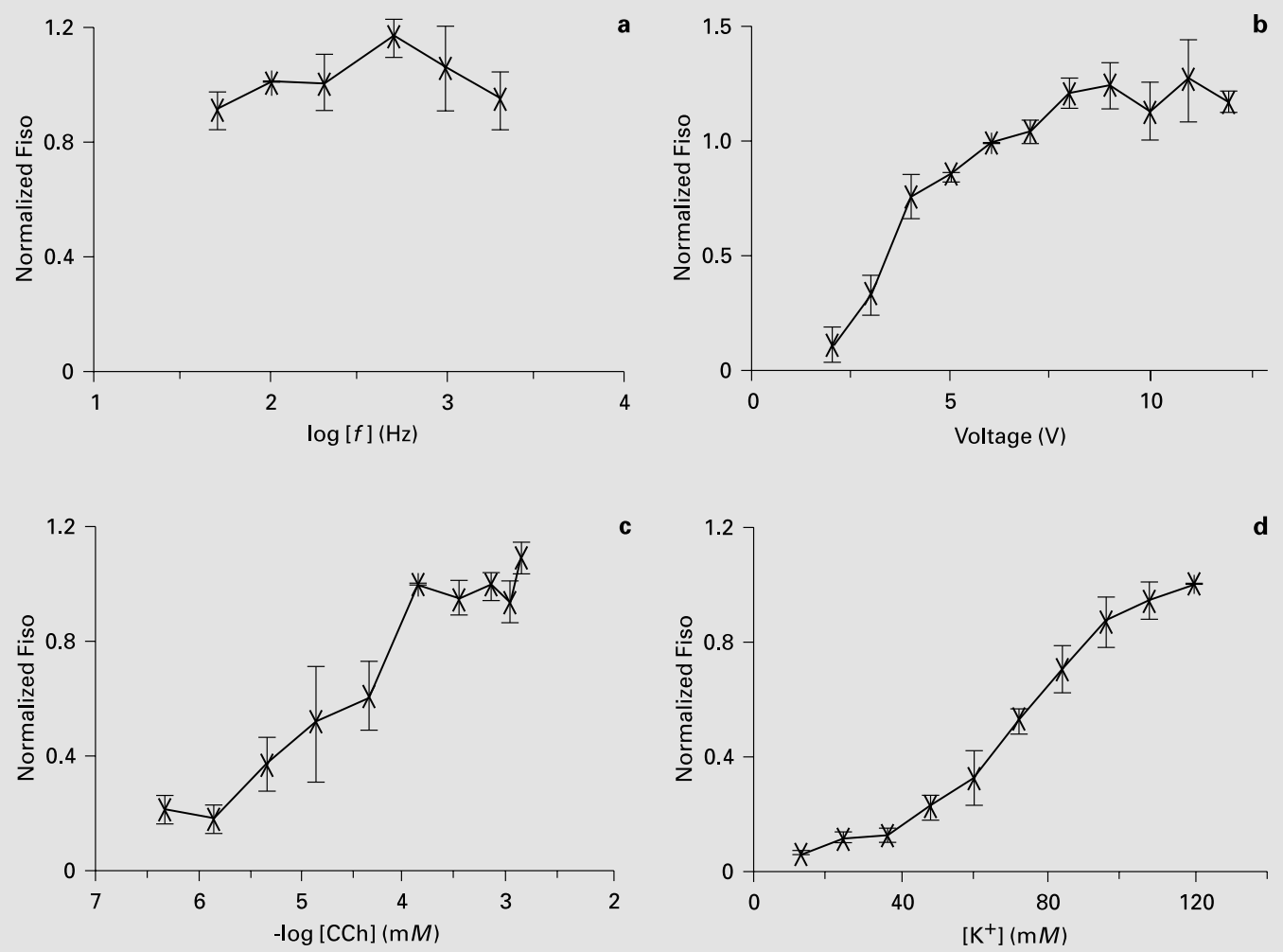

3

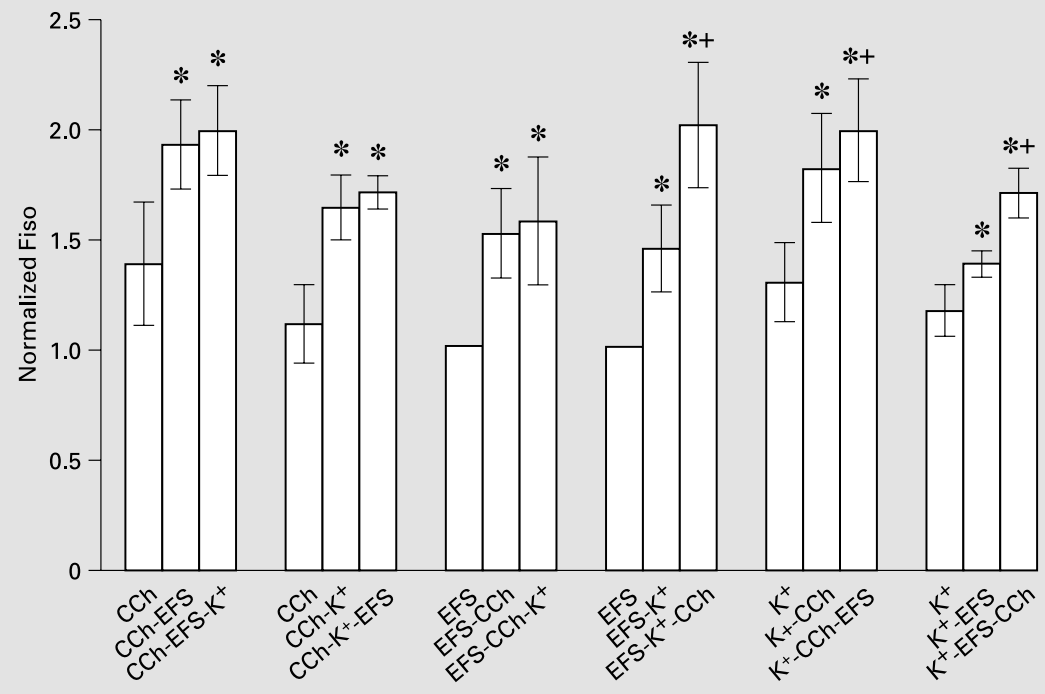

Fig. 3. Dose-response curves. a The dependence of the isometric force (Fiso) on the repetition rate of the stimulus. The amplitude was fixed at $6 \mathrm{~V}$ and the reference EFS was $100 \mathrm{~Hz}$ and $6 \mathrm{~V}$. b The voltage dependence of the isometric force with a reference EFS of $500 \mathrm{~Hz}$ and $6 \mathrm{~V}$. c The dependence of the isometric force on $\mathrm{CCh}$. As a reference concentration $0.14 \mathrm{~m} M \mathrm{CCh}$ was used. d The isometric force dependence on the $\mathrm{K}^{+}$concentration is shown and had a reference concentration of $119 \mathrm{mM} \mathrm{K}$.

Supramaximal Stimuli in Smooth Muscle
Fig. 4. Cumulative stimulation with the supramaximal stimuli. The 8 fibers were successively stimulated with all three supramaximal stimuli $\left(500 \mathrm{~Hz}, 8 \mathrm{~V}\right.$ EFS, $1.4 \mathrm{~m} M \mathrm{CCh}$ and $\left.119 \mathrm{~m} M \mathrm{~K}^{+}\right)$. All force values were divided by the response to EFS and averaged. The differences were tested with a paired $t$ test. ${ }^{*}$ Indicates when addition of a second or third stimulus resulted in a significantly higher force value than the force evoked by only the first stimulus $(p<0.05) .^{+}$Indicates when the force evoked by the combination of the first two stimuli significantly increased after adding the third stimulus $(p<0.05)$.

Urol Int 2001;67:62-68 
Fig. 5. Comparison of the force response to combined stimulation (indicated with a sign) with summation of the responses to separate stimuli (indicated with a + sign). Differences were tested with a paired t-test: $* \mathrm{p}<0.05$.

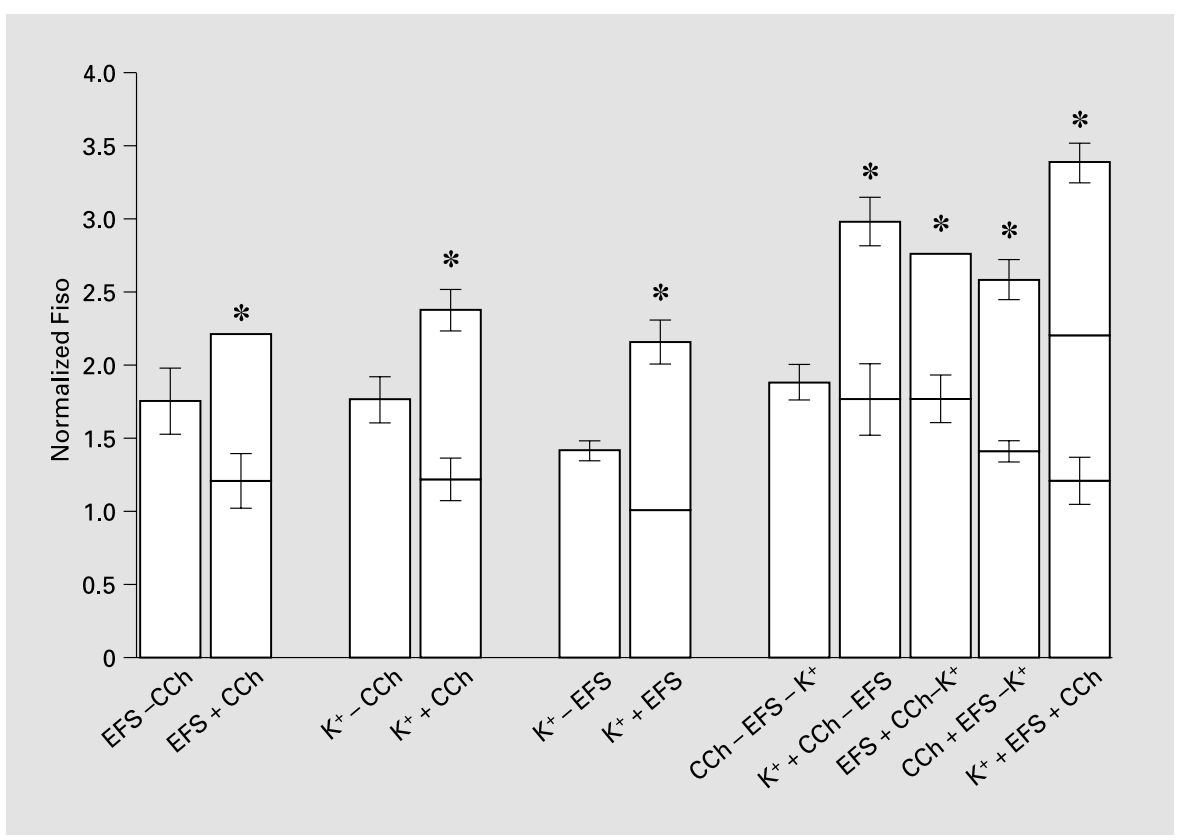

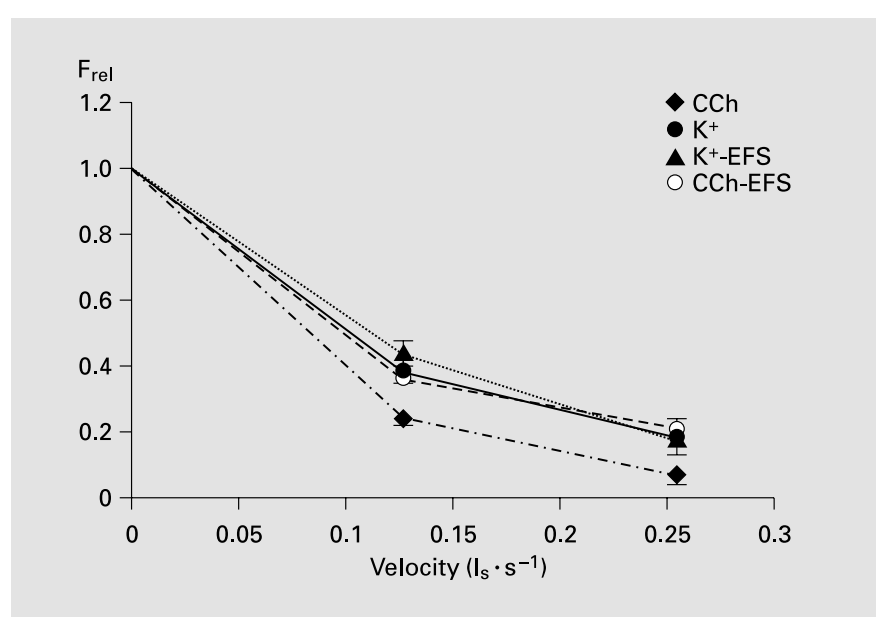

Fig. 6. The force velocity relation of the fibers stimulated with $\mathrm{CCh}$, $\mathrm{K}^{+}, \mathrm{CCh}-\mathrm{EFS}$ and $\mathrm{EFS}-\mathrm{K}^{+}$. The relative force $\left(\mathrm{F}_{\text {rel }}\right)$ is plotted on the $\mathrm{Y}$ axis and the shortening velocity normalized to the slack length on the $\mathrm{X}$ axis.

reached, a second stimulus was added and the force further increased to a new maximum value. This second values was singificantl higher than the first one for each combination of stimuli (paired t test, $\mathrm{p}<0.05$ ) and independent of the order of application and the combination of the stimuli (fig. 4; ANOVA, $p=0.257$ ). The response to a combined stimulus was in each case smaller than the sum of the responses to the two stimuli separately (fig. 5). When the isometric force value leveled off, a third stimulus was added and the force further increased to a new maximum value. This third isometric force value did not depend on the order of stimuli applied (ANOVA, $p=$ 0.662 ) and was lower than the summation of the three stimuli separately and also lower than the summation of the response to two combined stimuli and the third stimulus (fig. 4, 5; paired t test, $\mathrm{p}<0.05$ ).

\section{Force Velocity Relation}

Five fibers were shortened at two different velocities from a start length to a fixed stop length (fig. 2). The relative force, the force at the stop-length during shortening divided by the maximum force at that length, depended on the shortening velocity (fig. 6). At both velocities the relative forces were the same when the preparation was stimulated with $\mathrm{K}^{+}$alone, or $\mathrm{CCh}-\mathrm{EFS}$, or $\mathrm{K}^{+}$-EFS. When the strip was stimulated with $\mathrm{CCh}$ alone, the relative force was lower (paired $t$ test, $p<0.05$ ). As a result, the maximum shortening velocity measured with $\mathrm{CCh}$ alone was lower than that measured with $\mathrm{K}^{+}$alone, or with CCh-EFS and $\mathrm{K}^{+}$-EFS combined (fig. 7). The results were also compared with the maximum shortening velocity measured with EFS in a previous study [7]. The mean value of the maximum shortening velocity measured with EFS only differed from the one measured with $\mathrm{K}^{+}$-EFS ( $\mathrm{t}$ test, $\mathrm{p}<$ $0.05)$. 


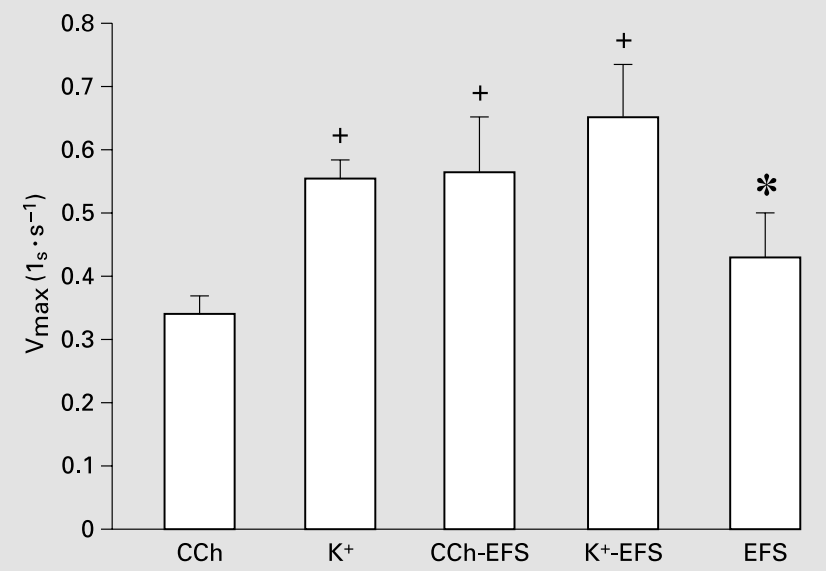

Fig. 7. The maximum shortening velocity $\left(\mathrm{V}_{\max }\right)$ measured with different combinations of stimuli. The maximum shortening velocities measured with $\mathrm{CCh}, \mathrm{K}^{+}, \mathrm{CCh}-\mathrm{EFS}$ or $\mathrm{EFS}-\mathrm{K}^{+}$were measured in the same 5 fibers. The maximum shortening velocity evoked by EFS was measured in a previous study $(\mathrm{n}=15)$ [7]. CCh differs significantly from $\mathrm{K}^{+}, \mathrm{EFS}-\mathrm{K}^{+}$and CCh-EFS $\left({ }^{+}\right.$paired $t$ test, $\left.\mathrm{p}<0.05\right)$ and EFS differs significantly from EFS- $\mathrm{K}^{+}(* t$ test, $\mathrm{p}=0.015)$.

\section{Discussion}

Carbachol, high potassium and electrical field stimulation are frequently used to evoke contractions of smooth muscle preparations. We tested whether concentrations, which are considered to be supramaximal, resulted in a maximum force development. We found in smooth muscle of the pig detrusor that none of the three supramaximal stimuli resulted in development of the maximum isometric force of that muscle. Addition of a second or even a third different supramaximal stimulus further increased the isometric force. We proved that each of our stimuli are supramaximal by measuring the dose-response curves, which were comparable to other such curves in the literature - EFS [10, 11], and $\mathrm{CCh}$ and $\mathrm{K}^{+}[12,13]$. It was shown earlier [14] that $\mathrm{CCh}$, in doses which were too low to initiate a contraction, increased electrical field evoked submaximal contractions. That a combination of two supramaximal stimuli results in a higher isometric force has, to our knowledge, not been published before.

High $\mathrm{K}^{+}$depolarizes the cell membrane, which results in the opening of voltage-dependent calcium channels and a subsequent rise in intracellular calcium [2, 3]. For vascular smooth muscles it has been observed that the increase in free intracellular calcium in response to epi- nephrine and $\mathrm{K}^{+}$stimulation was additive $[2,4,5]$. In these studies, the isometric force was not measured, so that we cannot assert whether the force response to $\mathrm{K}^{+}$ was maximal. However, the published results give evidence that $\mathrm{K}^{+}$stimulation does not result in a maximum free intracellular $\mathrm{Ca}^{2+}$ concentration. As the developed isometric force depends, within a certain range, on the $\mathrm{Ca}^{2+}$ concentration in the muscle cell [1], it is likely that $\mathrm{K}^{+}$stimulation does not completely activate the smooth muscle fiber.

Just like $\mathrm{K}^{+}$, EFS is expected to activate the muscle fiber by depolarizing the cell membrane. Indeed, the responses to both stimuli alone were comparable. Surprisingly, the addition of supramaximal EFS to supramaximal $\mathrm{K}^{+}$stimulation increased the isometric force. It seems inevitable to conclude that both $\mathrm{EFS}$ and $\mathrm{K}^{+}$partly address different calcium sources or open different populations of calcium channels. Alternatively, it is possible that in our preparation neither of these stimuli activated all cells. However, it should be kept in mind that our preparations were very small. We therefore assume that all cells were activated. If the effect of incomplete stimulation did occur, it would almost certainly also effect other preparations in other studies.

$\mathrm{CCh}$ binds to the muscarinic receptors in the cell membrane. This results in the release of intracellular calcium through second-messenger pathways. $\mathrm{CCh}$ might also effect the calcium sensitivity of the contractile elements [2, $3]$. $\mathrm{CCh}$ thus activates the cell differently from $\mathrm{K}^{+}$or EFS. Therefore, a combined stimulation of $\mathrm{CCh}$ with EFS or $\mathrm{K}^{+}$can increase the intracellular free calcium concentration or the same amount of intracellular calcium can result in a larger isometric force. This explanation implies that neither intracellular calcium release nor extracellular calcium influx results in a maximum contraction in the muscle cells. Again, the alternative explanation is that none of the stimuli reached all muscle cells. If $\mathrm{K}^{+}$and $\mathrm{CCh}$ do not reach all cells, this might be caused by an insufficient diffusion into the fibers. In that case we expect that, although both stimuli act differently on the cell, they reach the same cells.

The maximum shortening velocity in response to $\mathrm{CCh}$ stimulation was slightly lower than the one in response to $\mathrm{K}^{+}$alone, $\mathrm{CCh}$-EFS or $\mathrm{K}^{+}$-EFS. The maximum shortening velocity of the fiber depends on the intracellular calcium concentration $[15,16]$. As CCh increases not only the calcium concentration in the cell, but also the sensitivity of the sarcomeres for calcium [2,3], less calcium is needed to attain the same force value as with $\mathrm{EFS}$ or $\mathrm{K}^{+}$. Our results could therefore be explained by assuming that $\mathrm{CCh}$ stimu- 
lation changes the relationship between the intracellular calcium concentration and the isometric force, but not the one between the calcium concentration and the maximum shortening velocity.

$\mathrm{K}^{+}$and EFS are both expected to evoke a contraction solely by increasing the intracellular calcium concentration. Because their isometric forces are the same, it can be assumed that their intracellular calcium concentrations are also the same, therefore the same maximum shortening velocity is expected. Indeed we found that the maximum shortening velocity of EFS did not differ from the one reached with $\mathrm{K}^{+}$. However, there was also no difference with the one in response to $\mathrm{CCh}$ application. The maximum shortening velocity evoked by EFS was measured in different fibers than the other maximum shortening velocities though. There was a large difference in max- imum shortening velocity values between fibers [7], which might explain these results. It may also be that the different stimulation types have different effects on the sarcomere kinetics, but we are not able to make this conclusion from our data.

\section{Conclusions}

We conclude that in pig detrusor smooth muscle, $\mathrm{CCh}$, high $\mathrm{K}^{+}$and EFS address, at least partly, different activation pathways and none of them results in a maximal contraction. This effect of incomplete stimulation by a single supramaximal stimulus will most certainly also effect other studies.

\section{References}

1 Malmqvist U, Arner A, Uvelius B: Mechanics and $\mathrm{Ca}^{2+}$-sensitivity of human detrusor muscle bundles studied in vitro. Acta Physiol Scand 1991;143:373-380.

2 Karaki H, Ozaki H, Hori M, Mitsui-Saito M, Amano K, Harada K, Miyamoto S, Nakazawa H, Won K-J, Sato K: Calcium movements, distribution, and function in smooth muscle. Pharmacol Rev 1997;49:157-230.

3 Anderson K-E: Pharmacology of lower urinary tract smooth muscle and penile erectile tissues. Pharmacol Rev 1993;45:253-308.

4 Meisheri KD, Hwang O, van Breemen C: Evidence for two separate $\mathrm{Ca}^{2+}$ pathways in smooth muscle plasmalemma. J Membr Biol 1981;59:19-25.

5 Karaki H, Weiss GB: Alterations in high and low affinity binding of ${ }^{45} \mathrm{Ca}$ in rabbit aortic smooth muscle by norepinephrine and potassium after exposure to lanthanum and low temperature. J Pharmacol Exp Ther 1979;211:8692.
6 Karaki H, Weiss GB: Effects of stimulatory agents on mobilization of high and low affinity site ${ }^{45} \mathrm{Ca}$ in rabbit aortic smooth muscle. $\mathrm{J}$ Pharmacol Exp Ther 1980;213:450-455.

7 Minekus J, van Mastrigt R: Length dependence of the contractility of smooth muscle fibers. In press.

8 Van Koeveringe GA: Dynamics of smooth muscle contraction; thesis, Erasmus University Rotterdam, SBN 90-9010647-2, 1997.

9 Hill AV: The heat of shortening and the dynamic constants of muscle. Proc R Soc Lond B 1938; $126: 136$.

10 Van Mastrigt R, Glerum JJ: Electrical stimulation of smooth muscle strips from the urinary bladder of the pig. J Biomed Eng 1985;7:2-8.

11 Groen J, van Asselt E, van Mastrigt R, Bosch $\mathrm{R}$, van Koeveringe GA: Comparison of detrusor contractility of guinea pig bladders in situ and strips from these in vitro. J Urol 1993;150: 1002-1006.
12 Kishii K, Hisayama T, Takayanagi I: Comparison of contractile mechanisms by carbachol and ATP in detrusor strips of rabbit urinary bladder. Jpn J Pharmacol 1992;58:219-229.

13 Elliott RA, Norman RI, Parker SG, Whitaker RP, Castleden CM: Effect of treatment with calcium antagonists in vitro and in vivo on the contractile response of isolated rat and human detrusor muscle. Clin Sci 1996;91:467-474.

14 Masters JG, Neal DE, Gillispie JI: The contribution of intracellular $\mathrm{Ca}^{2+}$ release to contraction in human bladder smooth muscle. $\mathrm{Br} \mathrm{J}$ Pharmacol 1999; 127:996-1002.

15 Arner A, Malmqvist U: Cross-bridge cycling in smooth muscle: A short review. Acta Physiol Scand 1998;164:363-372.

16 Malmqvist U, Arner A: Regulation of force and shortening velocity by calcium and myosin phosphorylation in chemically skinned smooth muscle. Pflügers Arch 1996;433:42-48. 